\title{
Morten Mittelstädt
}

\section{Die Auslegung empfangsbedürftiger Willenserklärungen}

Eine Kritik des herrschenden Methodendualismus

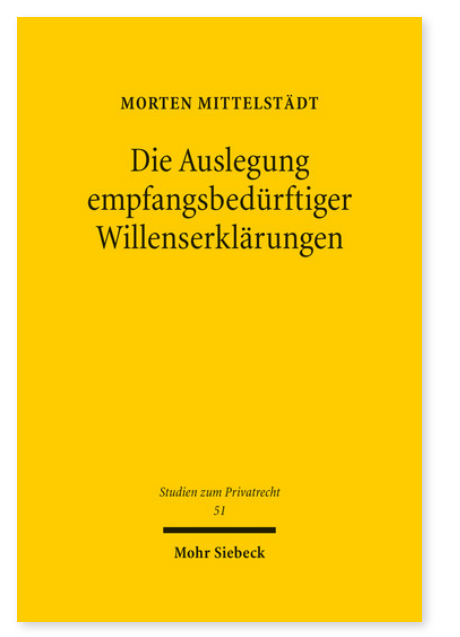

2016. XXVII, 409 Seiten. StudPriv 51

ISBN 978-3-16-154644-0

DOI 10.1628/978-3-16-154644-0

eBook PDF 114,00€

ISBN 978-3-16-154643-3

Leinen $114,00 €$
Nach heute allgemein anerkannter Lesart der §§ 133, 157 BGB gibt es zwei verschiedene Methoden der Auslegung empfangsbedürftiger Willenserklärungen, unter denen eine den Vorrang genießt: Gehen Erklärender und Empfänger innerlich bei Vornahme des Rechtsgeschäfts vom selben Erklärungssinn aus, soll dieser maßgeblich sein, selbst wenn die nachrangige normative Auslegung anhand des objektiven Empfängerhorizonts zu einem anderen Ergebnis gelangen würde (falsa demonstratio non nocet ). Morten Mittelstädt weist nach, dass diese dualistische Lehre mit einer Kernaufgabe der Rechtsgeschäftslehre, dem Schutz berechtigten Vertrauens, unvereinbar ist. Zum Schutz des Orientierungsinteresses der Beteiligten vertritt er das Gegenmodell einer streng normativen Auslegung nach dem objektiven Empfängerhorizont und behandelt dessen Folgefragen. Er schließt mit einem Ausblick auf Parallelfragen in internationalen Regelwerken.

Morten Mittelstädt Geboren 1980; Studium der Rechtswissenschaft an der Bucerius Law School, Hamburg ; 2006 Erste juristische Staatsprüfung; Juristischer Vorbereitungsdienst am Kammergericht; 2011 Zweite juristische Staatsprüfung; Wissenschaftlicher Mitarbeiter am Lehrstuhl für Bürgerliches Recht, Handels- und Wirtschaftsrecht und Rechtsvergleichung der Bucerius Law School (Prof. Dr. Florian Faust), Hamburg; Stipendiat der Studienstiftung des Deutschen Volkes; seit 2014 Notarassessor in der Freien und Hansestadt Hamburg.

Jetzt bestellen:

https://mohrsiebeck.com/buch/die-auslegung-empfangsbeduerftiger-willenserklaerungen-9783161546440?no_cache=1 order@mohrsiebeck.com

Telefon: +49 (0)7071-923-17

Telefax: +49(0)7071-51104 